\title{
Task 3: Validation Using Real-World Data
}

Mindy Gerdes, Don Scoffield, Jonathan Coignard

April 2017

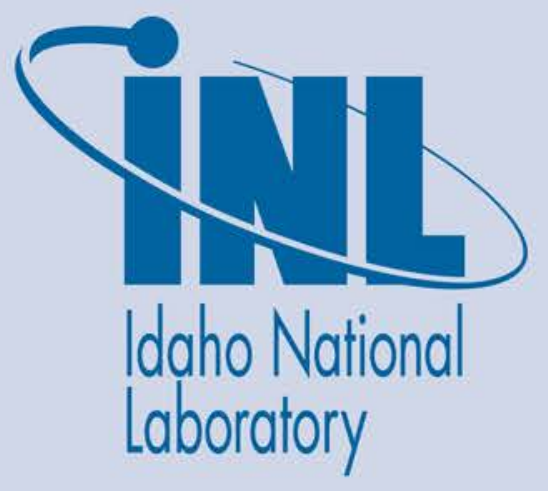

The INL is a U.S. Department of Energy National Laboratory operated by Battelle Energy Alliance 
INL/EXT-17-41872

\title{
Task 3: Validation Using Real-World Data
}

\author{
Mindy Gerdes, Don Scoffield, Jonathan Coignard
}

April 2017

\section{Idaho National Laboratory \\ Idaho Falls, Idaho 83415}

http://www.inl.gov

Prepared for the

U.S. Department of Energy

Office of Energy Efficiency/Renewable Energy (EE/RE)

Under DOE Idaho Operations Office

Contract DE-AC07-05ID14517 


\title{
Task 3: Validation Using Real-World Data
}

\author{
Mindy Gerdes (INL), Don Scoffield (INL) \\ Jonathan Coignard (LBNL) \\ June 5, 2017
}

\section{Introduction}

Idaho National Lab (INL) worked with the Lawrence Berkeley National Laboratory (LBNL) to validate the V2G-Sim predicted load profiles using real-world charging data from the San Diego Gas and Electric, Pacific Gas and Electric, and Los Angeles service areas collected from the Electric Vehicle Project (EV Project).

The EV Project is one of the largest deployment and evaluation project of electric drive vehicles and charging infrastructure to date. The data collection phase ran for three years (2011 to 2013) and captured almost 125 million miles of driving and 4 million charging events. Over 12,000 Alternative Current (AC) Level 2 (208-240V) charging units and over 100 dual-port Direct Current (DC) fast chargers were deployed in 20 metropolitan areas. Approximately 8,300 Nissan LEAF ${ }^{\text {TM }}$, Chevrolet Volts, and Smart ForTwo Electric Drive vehicles were also enrolled in the project.

The goal of this validation work is to compare V2G-Sim load demand forecast with the actual power demand measurement from the same set of Plug-In Vehicles (PEVs).

This validation work is necessary to gain confidence in the software's forecasts, and to identify the parameters with the most influence on the results. V2G-Sim should be able to forecast past situation before forecasting hypothetical scenarios in the future.

\section{Key tasks from the validation section (project task 3)}

\begin{tabular}{|l|l|l|l|}
\hline$\#$ & Tasks description & Status I Notes & Timeline \\
\hline 1 & $\begin{array}{l}\text { Streamline V2G-Sim validation process (the } \\
\text { validation process must be fast to allow multiple } \\
\text { iterations) }\end{array}$ & Done & $\begin{array}{l}\text { February, } \\
2017\end{array}$ \\
\hline 2 & $\begin{array}{l}\text { Validation of V2G-Sim capability to model } \\
\text { Battery Electric Vehicles (BEVs) }\end{array}$ & Done & December, \\
\hline 3 & $\begin{array}{l}\text { Validation of V2G-Sim capability to create } \\
\text { stochastic models for vehicle itinerary generation } \\
\text { (expand the database of itineraries using } \\
\text { statistical model) }\end{array}$ & Done & December, \\
\hline 4 & $\begin{array}{l}\text { Validation of V2G-Sim capability to model Plug- } \\
\text { In Hybrid Electric Vehicles (PHEVs) }\end{array}$ & Done & March, 2017 \\
\hline 5 & \begin{tabular}{l} 
Review with Energy Commission Staff \\
\hline
\end{tabular}
\end{tabular}




\begin{tabular}{|l|l|l|l|}
\hline 6 & Final revision & In progress & July, 2017 \\
\hline
\end{tabular}

\section{Validation Use Cases}

The validation is conducted for 6 use cases. The use cases were picked to cover different:

- Vehicle types

- Time periods

- Geographic locations

The use cases were limited by the available data from the EV project. The validation cases do not cover: rural areas, all the seasons, vehicles with longer driving range, or TOU pricings.

Nonetheless, the use cases selected provide a reference for the times of year when PEVs might have a substantial effect on the grid in cities with high level of PEV penetration using common vehicle models.

\begin{tabular}{|l|l|l|l|}
\hline ID & Time Period $^{*}$ & City & Vehicle \\
\hline 1 & Mar_2013 & San Francisco & Leaf \\
\hline 2 & Aug_2013 & San Francisco & Leaf \\
\hline 3 & Mar_2013 & San Diego & Leaf \\
\hline 4 & Mar_2013 & San Diego & Volt \\
\hline 5 & Aug_2013 & Los Angeles & Leaf \\
\hline 6 & Aug_2013 & Los Angeles & Volt \\
\hline
\end{tabular}

* Only weekdays in specified Time Periods were used because they show a higher charging activity and occur more often.

Future work should include use cases from multiple months, as well as including weekend travel patterns and a variety of TOU pricings. We don't foresee major impact on the final analysis when including rural areas, or more vehicle models.

\section{V2G-Sim Input Definitions:}

The following inputs were given to V2G-Sim to describe the charging behavior of all the PEVs in each use case.

- home_charger: probability to have a home charger $[0,1]$

- work_L1_charger: probability to have a level $1(120 \mathrm{~V})$ work charger $[0,1]$

- work_L2_charger: probability to have a level 2 (208/240 V) work charger [0, 1] - Note: work_L1_charger + work_L2_charger $<=1$.

- other_location_charger: probability to have a charger at other location than home or work $[0,1]$

- vehicle_max_charging_rate: maximum power at which a vehicle can be charged [Watt]

- is_phev: if FALSE the Nissan Leaf model is used in the simulation, if TRUE the Chevrolet Volt is used in the simulation

- ancillary_load_watt: constant power demand while driving where additional_energy = ancillary_load_watt*driving_duration_in_hour. 
- battery_efficiency: represent the energy loss when charging from the grid [0, 1].

- climate: the vehicle consumption is affected by the climate. Three options are available: COLD, TEMPERATE, HOT. Those options map to the consumption $(\mathrm{Wh} / \mathrm{mi})$ described in INL vehicle specification sheets (HOT at $95^{\circ} \mathrm{F}$, TEMPERATE at $72^{\circ} \mathrm{F}, \mathrm{COLD}$ at $20^{\circ} \mathrm{F}$ ) https://avt.inl.gov/sites/default/files/pdf/fsev/fact2013nissanleaf.pdf

- [home/work]_soc_no_charging: State Of Charge (SOC) beyond which user don't recharge their vehicle even if a charger is available $[0,1]$

- [home/work]_soc_charging: state of charge below which user always recharge their vehicle if a charger is available at the location $[0,1]$

The probability of plugging a PEV or not when a charging station is available is determined by soc_no_charging and soc_charging such that:

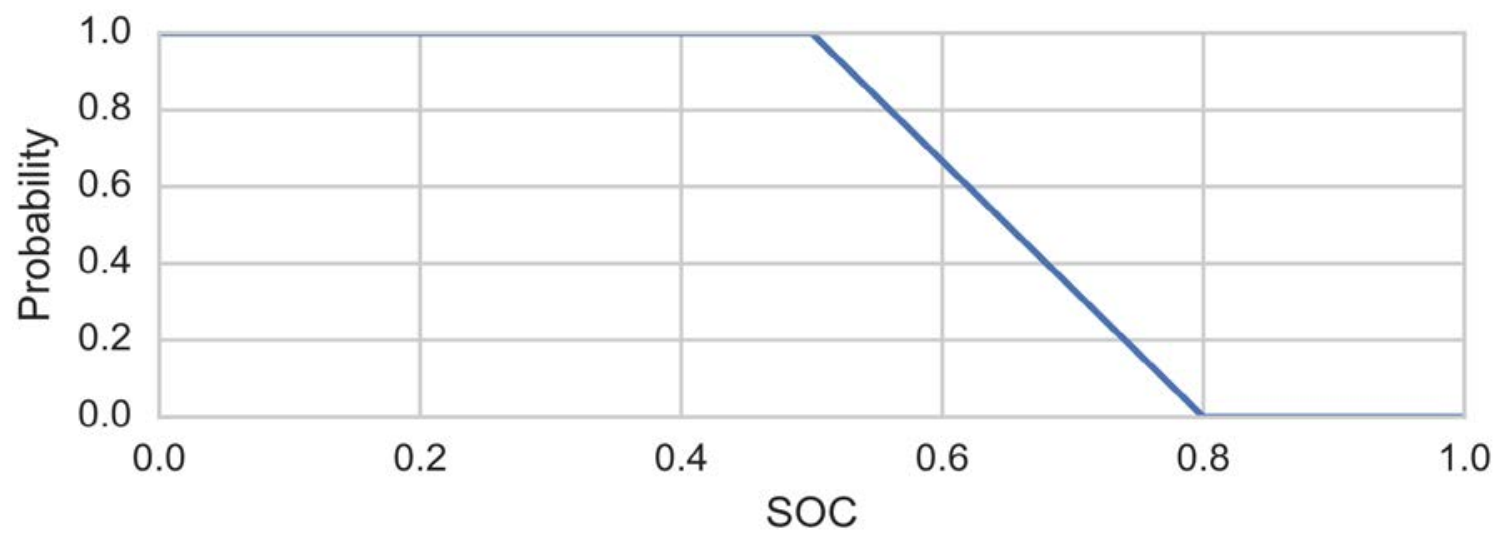

In this example: soc_no_charging $=0.8$, soc_charging $=0.5$

\section{Validation Methodology:}

INL's itineraries data set was sub-divided into two data sets, a training data set and a validation data set. INL staff adjusted the input parameters to V2G-Sim in order to make the output of V2G$\mathrm{Sim}$ as close as possible to the actual charging behavior (calibration process). Once the input parameters to V2G-Sim were calibrated, the same inputs were used on the validation data set. This process was followed for all six use cases.

In the charts below, actual charging profiles are compared with profiles from V2G-Sim for both the training and the validation sets, which are named Training Results and Validation Results, respectively.

\section{Input Parameters to V2G-Sim:}

The trained input parameters agree with what has been seen on the EV project. For instance, the Chevrolet Volt tends to use L1 charger at work whereas the Nissan Leaf exclusively use L2 chargers. This partially due to the fact that the Chevrolet Volt comes with an adapter for L1 chargers. 


\begin{tabular}{|lrrrrrr|}
\hline & $\begin{array}{c}\text { San Fran } \\
\text { March Leaf }\end{array}$ & $\begin{array}{l}\text { San Fran } \\
\text { Aug Leaf }\end{array}$ & $\begin{array}{l}\text { San Diego } \\
\text { Mar Leaf }\end{array}$ & $\begin{array}{l}\text { San Diego } \\
\text { Mar Volt }\end{array}$ & $\begin{array}{l}\text { Los } \\
\text { Angeles } \\
\text { Aug Leaf }\end{array}$ & $\begin{array}{l}\text { Los Angeles } \\
\text { Aug Volt }\end{array}$ \\
\hline home_charger & 1 & 1 & 1 & 1 & 1 & 1 \\
work_L1_charger & 0 & 0 & 0 & 0.4 & 0 & 0.4 \\
work_L2_charger & 0.7 & 0.7 & 0.78 & 0.45 & 0.78 & 0.4 \\
other_location_charger & 0.04 & 0.04 & 0.04 & 0.04 & 0.04 & 0.04 \\
home_soc_no_charging & 0.9 & 0.9 & 0.9 & 0.9 & 0.9 & 0.9 \\
home_soc_charging & 0.5 & 0.5 & 0.68 & 0.6 & 0.4 & 0.55 \\
work_soc_no_charging & 0.9 & 0.9 & 0.9 & 0.9 & 0.9 & 0.9 \\
work_soc_charging & 0.7 & 0.65 & 0.65 & 0.65 & 0.75 & 0.6 \\
vehicle_max_charging_rate & 3300 & 3300 & 3300 & 3140 & 3300 & 3140 \\
battery_efficiency & 0.89 & 0.89 & 0.89 & 0.88 & 0.89 & 0.88 \\
is_phev & FALSE & FALSE & FALSE & TRUE & FALSE & TRUE \\
ancillary_load_watt & 200 & 200 & 1500 & 500 & 80 & 800 \\
climate & TEMPERATE & TEMPERATE & TEMPERATE & TEMPERATE & TEMPERATE & TEMPERATE \\
\hline
\end{tabular}

Table - result of the calibration process, best fit for each of the 6 use cases.

\section{San Francisco, Leaf, March 2013}
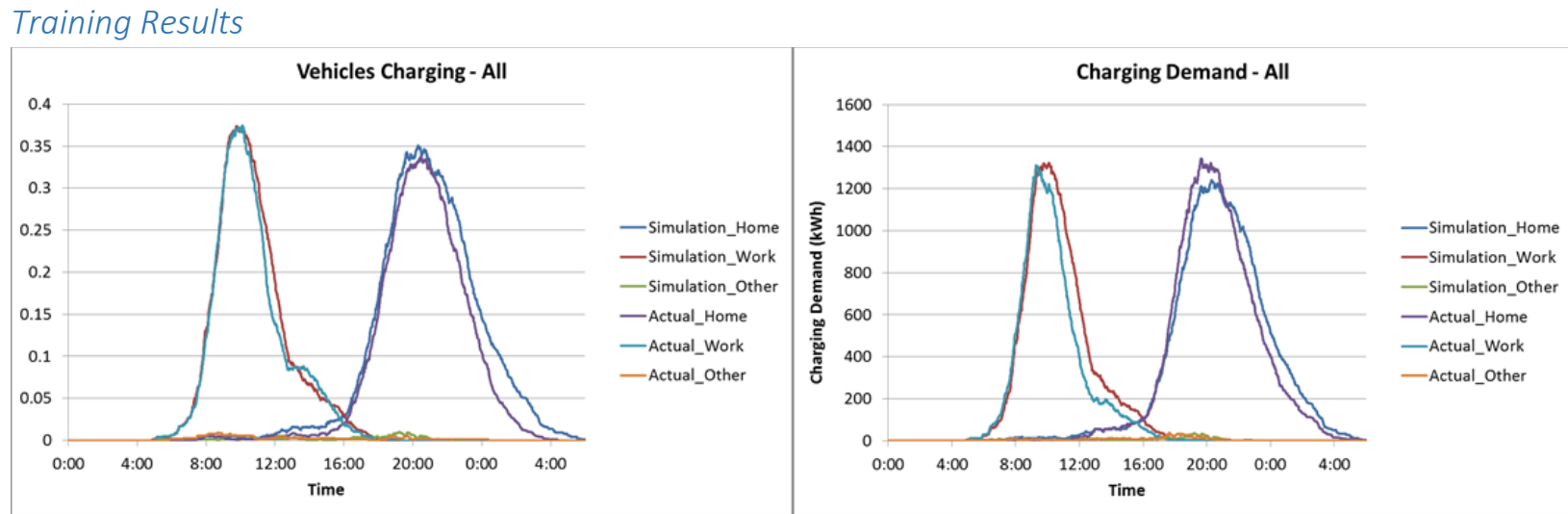

Validation Results
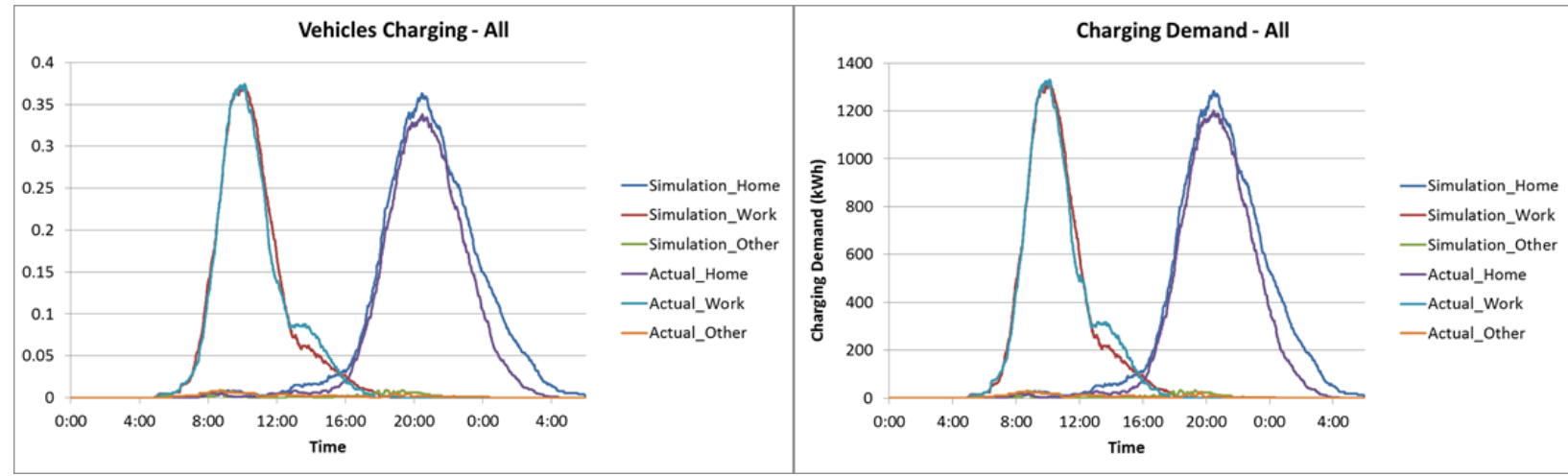


\section{San Francisco, Leaf, August 2013}

\section{Training Results}

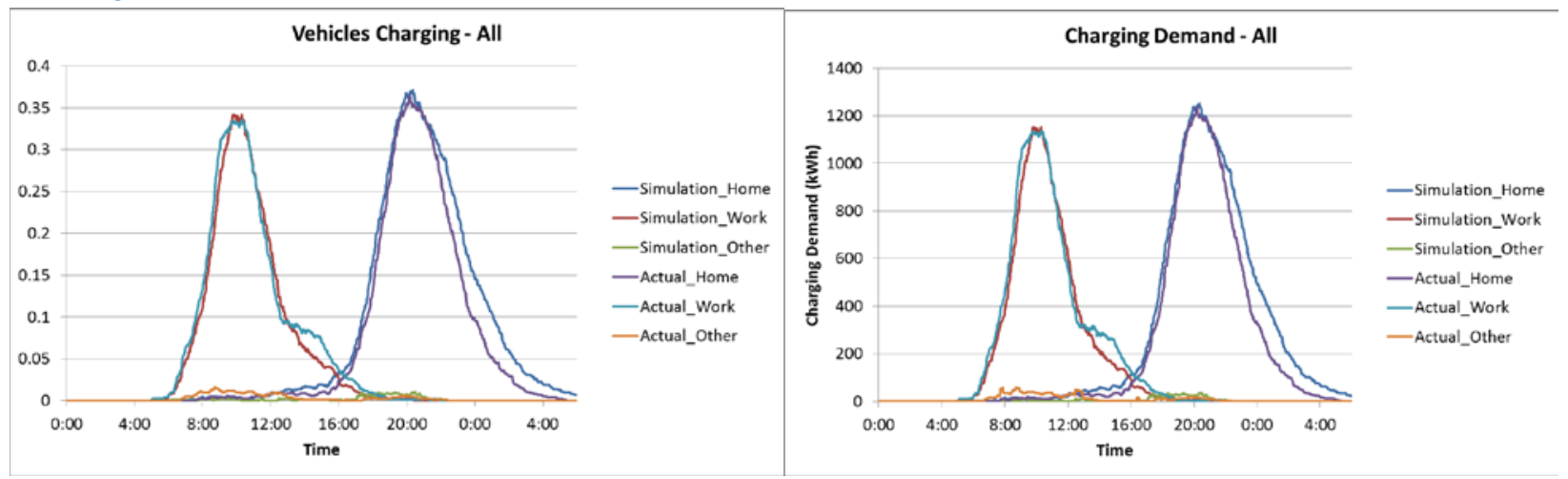

\section{Validation Results}
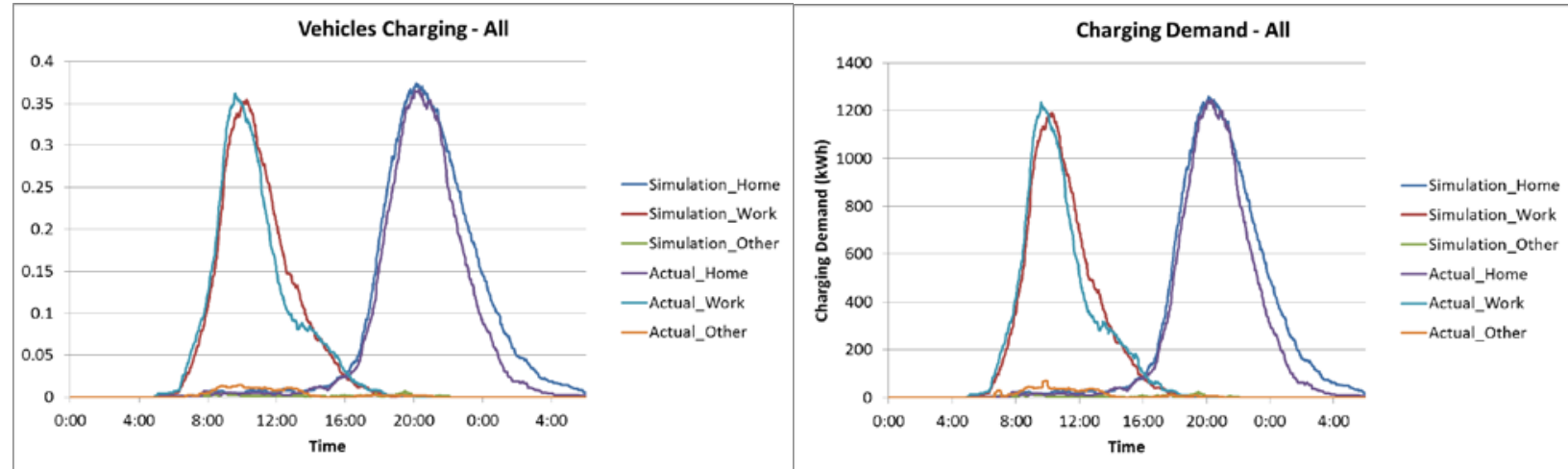


\section{San Diego, Leaf, March 2013}

\section{Training Results}

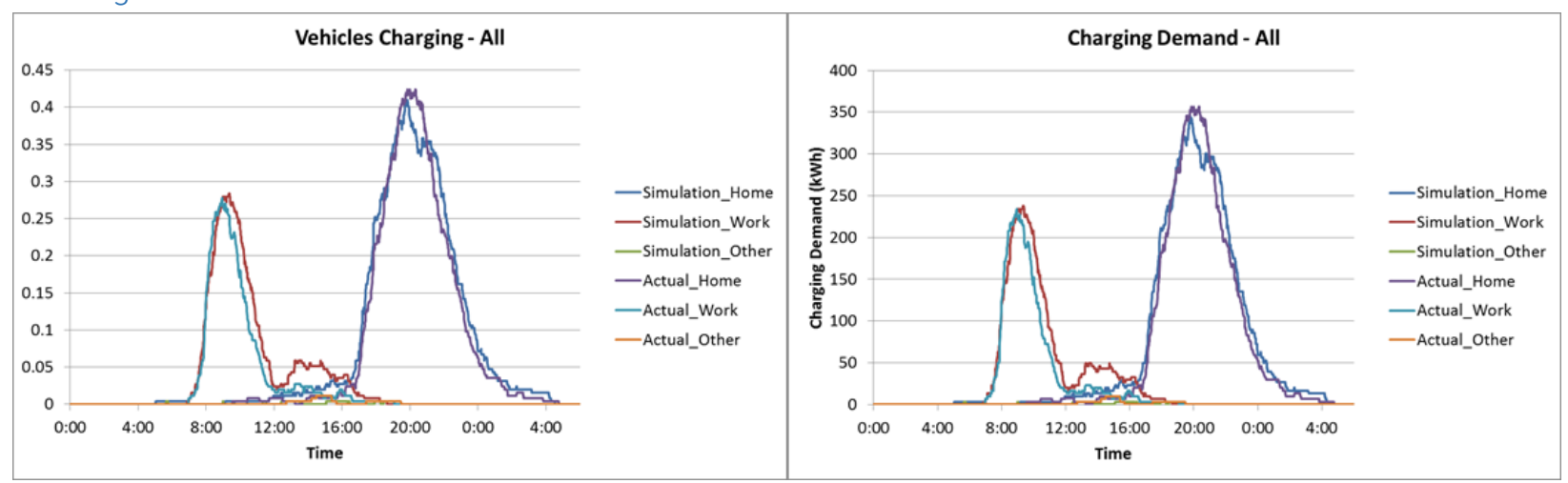

\section{Validation Results}

Chicles Charging - All




\section{San Diego, Volt, March 2013}

Training Results

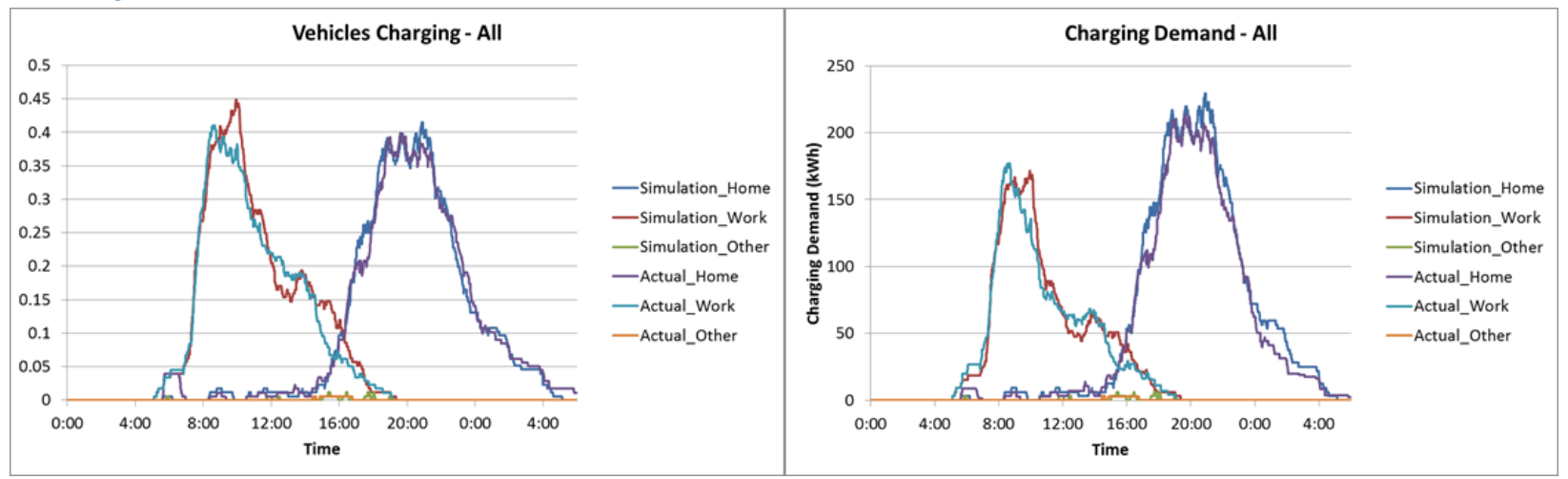

\section{Validation Results}
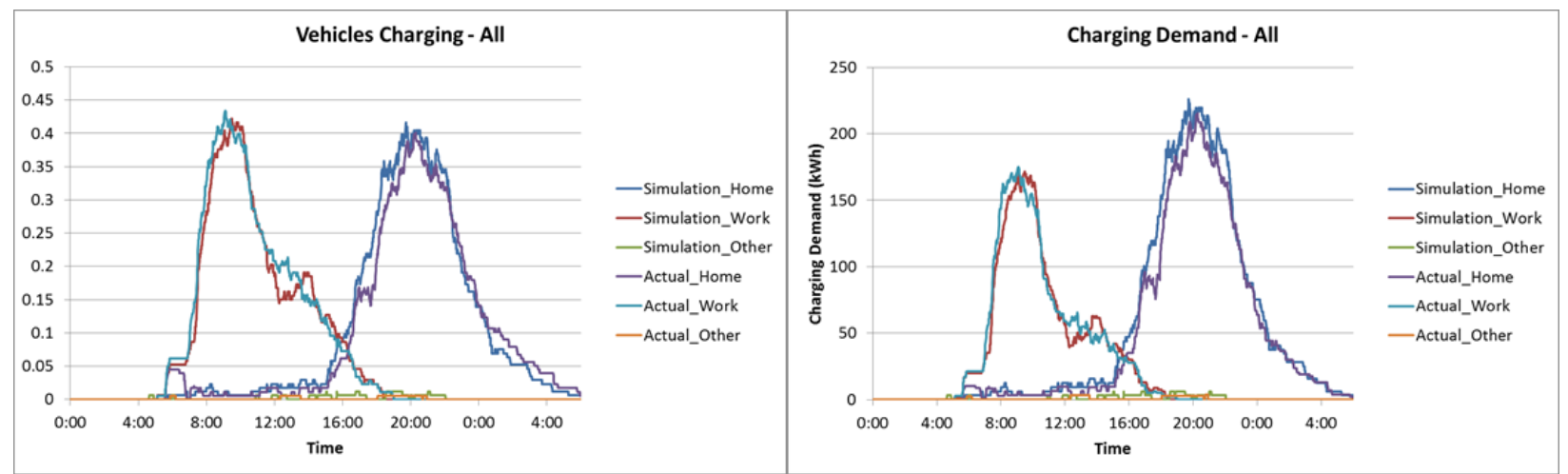


\section{Los Angeles, Leaf, August 2013}

\section{Training Results}

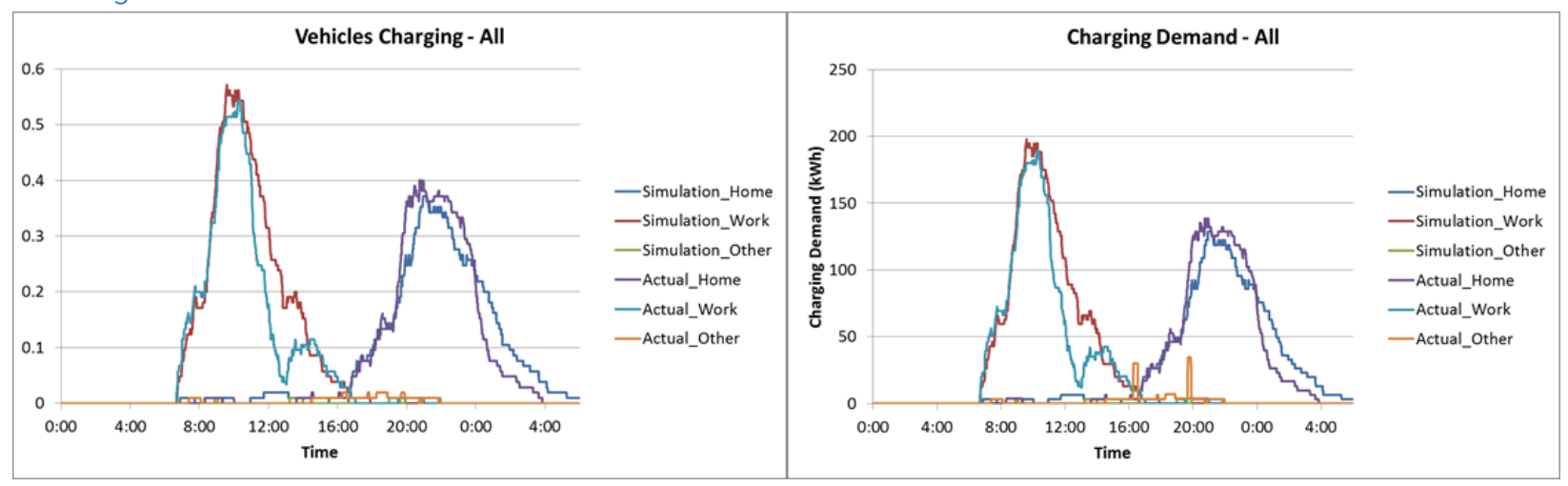

\section{Validation Results}
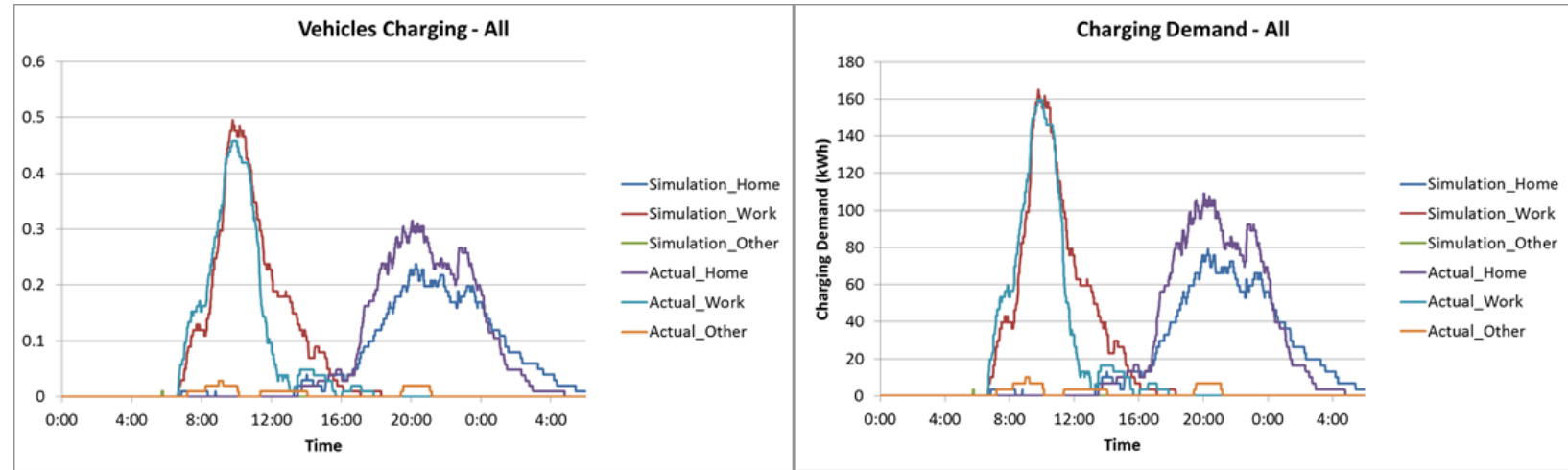


\section{Los Angeles, Volt, August 2013}

\section{Training Results}

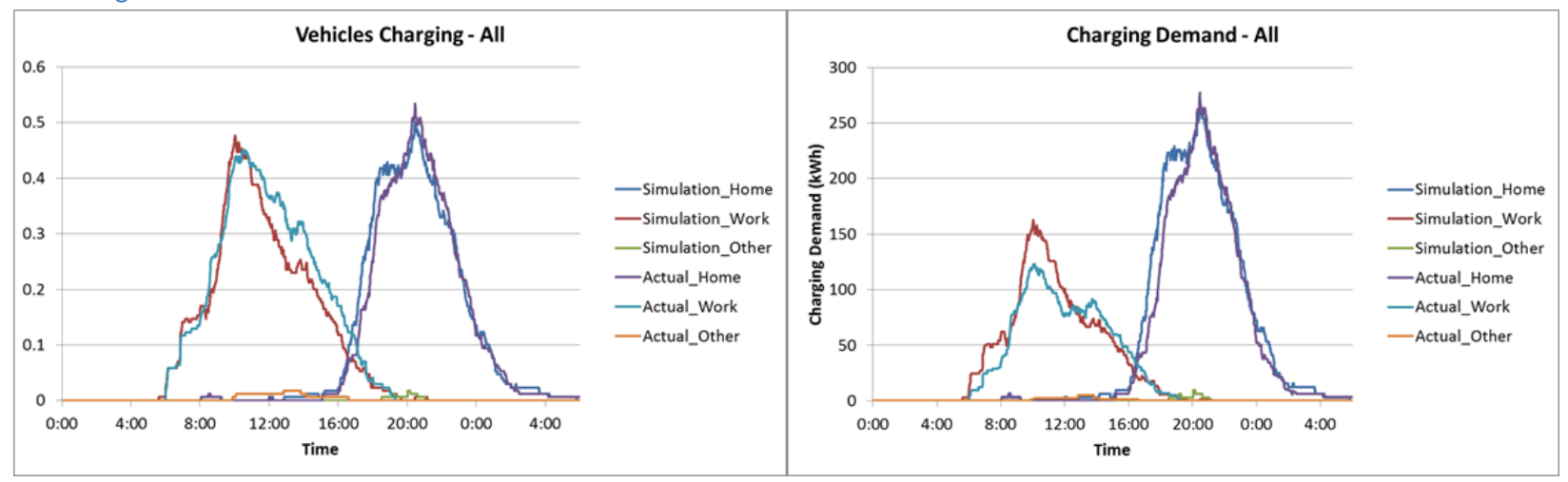

\section{Validation Results}
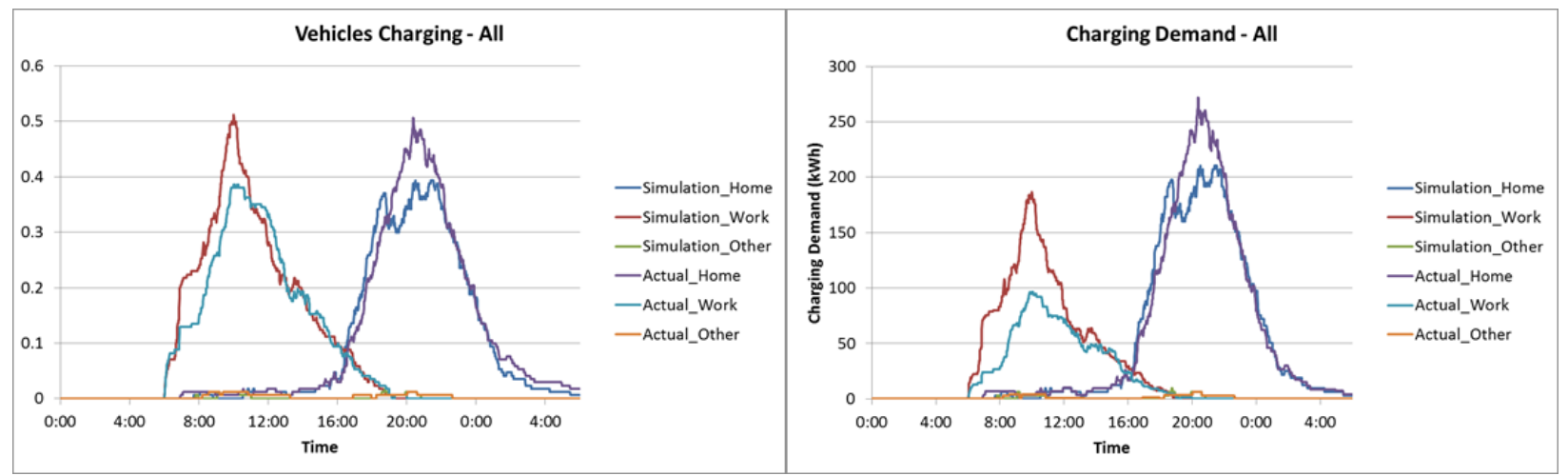

\section{Summary:}

Looking at the use case comparison charts above, in most cases V2G-Sim can match the actual charging curves reasonably well when given the proper training, this achieves the main goal of the validation work.

During the training process, INL staff noticed that the output demand curves from V2G-Sim are very sensitive to small changes in a few input parameters:

1. The likelihood of a charger being available at home, work, or other locations

2. The parameters which describe how the State of Charge of the vehicle influences the decision of whether to charge when there is a charger available at home and work locations

3. The ambient temperature 
While 1) and 2) tend to shift the power demand between home and workplace locations, 3) tends to increase the magnitude of PEV charging energy as higher temperature increases the use of air conditioning systems.

As a result, the challenge in using V2G-Sim to forecast future load curves is in accurately estimating the input values. Sensitivity analysis on the input parameters mentioned above may be necessary when using V2G-Sim to construct future load forecasts.

INL/EXT-17-41872 